\title{
Kinsenoside inhibits the inflammatory mediator release in a type-II collagen induced arthritis mouse model by regulating the $T$ cells responses
}

\author{
Hung-Bo Hsiao', Chang-Chi Hsieh², Jin-Bin Wu ${ }^{3}$, Ho Lin ${ }^{1}$ and Wen-Chuan Lin ${ }^{3 *}$
}

\begin{abstract}
Background: Anoectochilus formosanus has been used as a Chinese folk medicine and is known as the "King of medicine" in Chinese society due to its versatile pharmacological effects such as anti-hypertension, anti-diabetes, anti-heart disease, anti-lung and liver diseases, anti-nephritis and anti-Rheumatoid arthritis. Kinsenoside is an essential and active compound of A. formosanus (Orchidaceae). However, the anti-arthritic activity of kinsenoside has still not been demonstrated. In the present study, we confirmed that the kinsenoside treatment rheumatoid arthritis induced by collagen-induced arthritis in mice.
\end{abstract}

Methods: Male DBA/1 J mice were immunized by intradermal injection of $100 \mu \mathrm{g}$ of type II collagen in CFA. Kinsenoside was administered orally at a dose of 100 and 300 mg/kg once a day after 2nd booster injection. Paw swelling, arthritic score and histological change were measured. ELISA was used to measure cytokines including tumor necrosis factor alpha (TNF-a), interleukin-10 (IL-10), interleukin-17 (IL-17) and interferon- $\gamma$ (IFN- $\gamma$ ) in the splenocyte according to the manufacturer's instructions.

Results: Compared with model group, kinsenoside significantly inhibited paw edema and decreased the arthritis score and disease incidence. Histopathological examination demonstrated that kinsenoside effectively protected bone and cartilage of knee joint from erosion, lesion and deformation versus those from the CIA group. Kinsenoside also decreased IL-1 $\beta$, TNF- $\alpha$, and MMP-9 expression, and increased the expression of IL-10 in inflamed joints. The administration of kinsenoside significantly suppressed levels of TNF- $\alpha$, IFN- $\gamma$, and IL-17, but increased concentrations of IL-10 in the supernatants of each of the splenocytes in CIA mice compared with that in the $\mathrm{H}_{2} \mathrm{O}$ treated mice with CIA. Using flow cytometric analysis, we demonstrated that kinsenoside increases the population of $\mathrm{CD}^{+} \mathrm{CD}_{25} 5^{+}$regulatory T cells, thereby inhibiting the Th1 cell and B cell populations. Anticollagen IgG1 and IgG2a levels decreased in the serum of kinsenoside-treated mice.

Conclusions: These results suggest that the administration of kinsenoside effectively suppressed inflammatory mediators' production and bone erosion in mice with collagen-induced arthritis showing the potential as an antiarthritis agent.

Keywords: CIA, Kinsenoside, Rheumatoid arthritis, Inflammation

\footnotetext{
* Correspondence: wclin@mail.cmu.edu.tw

${ }^{3}$ School of Pharmacy, China Medical University, Taiwan. 91 Hsueh Shih Road,

Taichung 404, Taiwan, ROC

Full list of author information is available at the end of the article
} 


\section{Background}

Rheumatoid arthritis (RA) is a chronic inflammatory disease, characterized by the occurrence of inflammatory synovitis, which leads to the destruction of cartilage and bone within joints through inflammatory cells that migrate to the synovial and periarticular tissues [1]. In states of chronic inflammation, such as in RA, the imbalance between proinflammatory and antiinflammatory cytokines determines the degree and extent of inflammation causing cellular damage [2]. Proinflammatory cytokines, including TNF- $\alpha$, IL-17, IL-6, and IFN- $\gamma$, are the main mediators that initiate and cause inflammation to persist in RA, whereas antiinflammatory cytokines such as IL-4 and IL-10 can inhibit these processes [3]. Researchers have hypothesized that early inflammatory $\mathrm{T}$ cells, such as Th1 cells, play a critical role in the development of RA [1], and that Th1 cells (except for Th17 cells) are predominant in the joints of patients with RA, whereas Th2 cells, which suppress antigen-specific immune responses, are decreased [4]. Recently, the focus of research has expanded from Th1 and Th2 cells to regulatory $\mathrm{T}$ cells (Tregs), which can maintain immune homeostasis [5]. Current treatment modalities for RA either provide symptomatic relief (nonsteroidal antiinflammatory drugs; NSAIDs) or modify the disease process (disease-modifying antirheumatic drugs; DMARDs). According to the guidelines of the American College of Rheumatology, patients with newly diagnosed RA are strongly recommended to begin dual treatment by using NSAIDs to relieve nociceptive pain and control inflammation, and DMARDs to reduce disease activity, prevent joint deformity, and improve joint function [6]. The administration of these drugs is limited by the severe adverse effects of the drugs, such as gastrointestinal lesions, cardiovascular complications, and reproductive toxicity [7]. Therefore, researchers are focusing increasingly on plant-derived antiRA drugs with high efficacy and few side effects. Recent studies have estimated that $60-90 \%$ of patients with RA are highly likely to use botanical products [8]. This growing interest in alternative medical practices clearly indicates the necessity for more safe and effective anti-RA botanicals used in traditional medicine.

Anoectochilus formosanus has been used as a Chinese folk medicine and is known as the "King of medicine" in Chinese society due to its versatile pharmacological effects such as anti-hypertension, anti-diabetes, anti-heart disease, anti-lung and liver diseases, anti-nephritis and antiRheumatoid arthritis [9]. Therefore, A. formosanus extract is often used as a health supplement in Taiwan. Kinsenoside [3-(R)- $\beta$-D-glucopyranosyloxybutanolide] is an essential and active compound of $A$. formosanus (Orchidaceae) [10]. In previous studies, we discovered that kinsenoside ameliorated lipopolysaccharide (LPS)-induced shock in mice, and carbon tetrachloride caused hepatitis in mice by inhibiting macrophage activation $[11,12]$. Kinsenoside significantly inhibited the LPS-induced production of nitric oxide in both peritoneal lavage macrophages and RAW 264.7 cells in mice by suppressing NF- $\mathrm{B}$ activation [11]. In addition, we discovered that a standardized aqueous extract of $A$. formosanus modulated Tregs, thereby increasing the immunosuppression of airway hyperresponsiveness in mice that inhaled ovalbumin [13]. Therefore, kinsenoside may be able to downregulate both autoimmune and inflammatory responses in mice with collagen-induced arthritis (CIA). Although as far as we know, no studies have focused on the in vivo effects of kinsenoside. We encourage researchers to evaluate the anti-arthritic effects of kinsenoside in future studies.

In this study, we evaluated the immunomodulatory role of Tregs following the administration of kinsenoside during the initiation and establishment of arthritis in mice with CIA. Furthermore, we discussed the immunomodulatory role of Tregs following the administration of kinsenoside in proinflammatory cytokine release, and the resulting decrease in matrix metalloproteinases (MMP)-9 expression.

\section{Methods \\ Animals}

Male DBA/1 J mice were obtained from the Jackson Laboratory (Bar Harbor, Maine, USA), and were housed in standard laboratory cages and allowed access to tap water ad libitum. The experimental animals were housed in an air-conditioned room at $22-25{ }^{\circ} \mathrm{C}$ under a $12 \mathrm{~h}$ light-dark cycle. All animals were treated in accordance with the Institutional Animal Care and Use Committee (IACUC) of China Medical University, and the study protocol was approved by the ethics committee of the China Medical University, Taichung, Taiwan.

\section{Preparation of kinsenoside}

Kinsenoside was prepared by Associate Professor Wu. Fresh whole plants of A. formosanus (10 kg) were extracted with water and the filtrate was partitioned successively with ethyl acetate. Water-soluble portions (AFEW) were evaporated under reduced pressure, yielding 218.4 g of red residue. AFEW (210 g) was applied to a DIAION HP-20 column (Nippon Ressui Co., Japan) and eluted with $\mathrm{H}_{2} \mathrm{O}, 10,20$, and $50 \%$ methanol in water, and $100 \%$ methanol to provide five fractions (AFEW-1-AFEW-5). The dry weight of fraction AFEW-2 was $22.1 \mathrm{~g}$. Fraction AFEW-2 (10 g) was further purified using silica gel ( $\mathrm{Si}$ 60 F245; Merck, Germany) with chloroform/ethanol $(15: 8)$ as the mobile phase to provide four fractions. Fraction 4 (4.5 g) was applied to preparative high-performance liquid chromatography (HPLC) to yield a pure compound (4.1 g). Conditions used for the preparation of HPLC were as follows: pump, Shimadzu LC-8A (Kyoto, Japan); mobile phase, water; column, Mightysil ODS RP-18 Aqua column (i.d. $20 \mathrm{~mm}, 250 \mathrm{~mm}$ long; $5 \mu \mathrm{m}$ particle size; Kanto 
Chemical Co., Tokyo, Japan). The pure compound was identified by mass spectroscopy (Jeol GCmate, Tokyo, Japan). The content of kinsenoside was measured using HPLC. The conditions of HPLC were the same as those described in a previous study [14]. The identity and purity of the kinsenoside (>85 \%) was analyzed using highperformance liquid chromatography based on a previous study [14].

\section{Induction and assessment of collagen-induced arthritis}

CIA is typically induced using intradermal immunization with type II collagen (CII) in Freund's complete adjuvant (CFA, Sigma-Aldrich, St. Louis, MO, USA), followed by an intradermal booster immunization after 21 days [15]. In brief, CII purchased from Sigma-Aldrich (St. Louis, MO, USA) was reconstituted at $2 \mathrm{mg} / \mathrm{ml}$ in $50 \mathrm{mM}$ acetic acid. Mice received an intradermal injection of $100 \mu \mathrm{g}$ of CII in CFA (Day 0, primary immunization), and a booster injection of $100 \mu \mathrm{g}$ of CII in Freund's incomplete adjuvant (Sigma-Aldrich, St. Louis, MO, USA) on Day 21 (2nd booster injection). Following a prophylactic dosing program, the animals were randomly divided into four experimental groups, each containing six individuals, and treated follows:

Naive: no treat, normal.

CIA control: $\mathrm{H}_{2} \mathrm{O} 1 \mathrm{ml} / \mathrm{kg}$ p.o.

$\mathrm{CIA}+$ kinsenoside $100 \mathrm{mg} / \mathrm{kg}$ : kinsenoside $100 \mathrm{mg} / \mathrm{kg}$ p.o.

CIA + kinsenoside 300 mg/kg: kinsenoside 300 mg/kg p.o.

The mice were orally administered kinsenoside (100 or $300 \mathrm{mg} / \mathrm{kg}$ in water) daily, from Day 1 to Day 21 after 2nd booster injection, and monitored for disease incidence and severity up to Day 21. The CIA control mice were administered water alone.

Arthritic severity scores were derived as follows: The clinical scores for paws were used to reflect the severity of arthritis, and were classified as 0 (normal joints), 1 (swelling in one digit or joint inflammation), 2 (swelling in two or three digits, or slight paw swelling), 3 (swelling in more than four digits and moderate swelling in the entire paw), and 4 (severe swelling and deformation of the paw, also presenting rigid joints); the sum of the scores of all four paws of each mouse represented the total clinical score. Cumulative disease scores were calculated by adding the daily disease scores from the day following immunization onward, until the end of the experiment. The incidence of arthritic paws was defined as the occurrence of inflamed paws with a clinical arthritis score of 2 or higher among four paws.

On Day 21, all of the mice were anesthetized and blood was collected using cardiac puncture; the mice were then sacrificed using cervical dislocation after 2nd booster injection. The mice spleens were removed and used for enzyme-linked immunosorbent assay (ELISA) analysis, total cell count, flow-cytometric analysis, and histological and histochemical examinations.

\section{Identification of anticollagen antibodies in serum}

Identification of anticollagen antibodies in serum followed according to the procedure of Poosarla et al. (2011) [16]. Serum collected at the end of the experiment was stored at $-80{ }^{\circ} \mathrm{C}$. The level of anti-CII antibodies was measured using ELISA analysis. In brief, $200 \mu \mathrm{l} /$ well of CII $(10 \mu \mathrm{g} / \mathrm{ml})$ in phosphate-buffered saline (PBS) was coated on plates at $4{ }^{\circ} \mathrm{C}$, and left to stand overnight. After washing, the plates were treated with blocking buffer solution $(50 \mathrm{mM}$ Tris, $0.14 \mathrm{M} \mathrm{NaCl}$, $1 \%$ BSA, pH 8.0) for $30 \mathrm{~min}$. After washing the plates, the samples $(100 \mu \mathrm{l} /$ well $)$ were incubated for $90 \mathrm{~min}$ at room temperature. After washing the plates,, the plates were incubated with horseradish-peroxidase (HRP)-conjugated goat antimouse IgG1, or IgG2a (Bethyl Laboratories, Inc., Montgomery, TX, USA) for $60 \mathrm{~min}$. After washing, the plates were placed in tetramethylbenzidine (TMB; Kirkegaard \& Perry Laboratories, Gaithersburg, MD, USA) substrate solution, and incubated at room temperature for $30 \mathrm{~min}$. The enzymatic reaction was terminated by adding $50 \mu \mathrm{l}$ of stop solution $\left(2 \mathrm{M} \mathrm{H}_{2} \mathrm{SO}_{4}\right.$ ), and the absorbance of each well was measured at $450 \mathrm{~nm}$ (TRIAD multimode reader, Dynex Technologies, Sullyfield Circle, USA).

\section{Cll-induced cytokine production}

Splenocytes were collected from all groups, both with and without CIA immunization ( $n=6$ for all groups) on Day 21 of the prophylactic protocol, and seeded with $1 \times 10^{6}$ cells/well in RPMI-1640 supplemented with $10 \%$ FBS, and cultured for $48 \mathrm{~h}$ with or without $5.0 \mu \mathrm{g} / \mathrm{ml}$ Con A (Sigma-Aldrich St. Louis, MO, USA) in 24-well plates. Supernatants were collected and stored at $-80{ }^{\circ} \mathrm{C}$. Cytkine concentrations, including TNF- $\alpha$, IFN- $\gamma$, IL-10 (eBioscience, San Diego, CA, USA), and IL-17 (R\&D Systems Inc., Minneapolis, MN, USA), were measured using by ELISA according to the manufacturer's protocol

\section{Gene expression analysis}

RNA was extracted from the left hind paws of the mice, snap-frozen in liquid nitrogen, ground into powder, and homogenized. This procedure was conducted under RNase-free conditions. Total RNA was extracted from the tissue homogenates by using TRIzol (Invitrogen; Carlsbad, CA, USA) according to the manufacturer instructions. The total RNA $(3 \mu \mathrm{g})$ was subjected to room temperature reaction by using Moloney murine leukemia virus reverse transcriptase (M-MuLV, Hopegen Biotechnology, Taichung, 
Taiwan, ROC) according to the directions in the instruction manual. The specific primers are listed in Table 1 . The cDNA was amplified with a combination of sense and antisense primer pairs and PCR master mix (Fermentas International Inc., Burlington, Canada) by using a thermal cycler (Astec, Tokyo, Japan).

\section{Flow cytometric analysis}

Splenocytes were collected for analysis by using flow cytometry. Single-cell suspensions, both with and without CIA, were identified by detecting surface markers with the specific binding of monoclonal antibodies (mAb). In brief, $50 \mu \mathrm{l}$ of cell suspension $\left(5 \times 10^{5}\right.$ cells $)$ was incubated in the presence of saturating concentrations of fluorescein-, phycoerythrin-, or PE-Cy5-conjugated mAb (eBioscience, San Diego, CA., USA) on ice for $30 \mathrm{~min}$ in darkness. Cytofluorometric analysis of the lymphocyte fractions was performed using side scatter and forward scatter with laser excitation at $488 \mathrm{~nm}$. Flow cytometric data acquisition and analysis of cell populations of at least $1 \times 10^{4}$ leukocytes were performed on a CellQuest computer system (BD Biosciences). Percentage list mode data were calculated based on the number of lymphocytes identified in each quadrant. B cells were determined using the surface markers CD19+ (clone MB19-1) and CD45 (clone 30F11), T helper 1 (Th1) cells were determined using $\mathrm{CD}^{+}$(clone RM4-5) and $\mathrm{Tim}^{+} 3^{+}$(clone 8B.2C12), and Tregs were determined using $\mathrm{CD}^{+}$and $\mathrm{CD} 25^{+}$ (clone 7D4).

Table 1 PCR primers

\begin{tabular}{|c|c|c|c|c|}
\hline Gene name & primers & $\mathrm{bp}$ & cycle & $\left({ }^{\circ} \mathrm{C}\right)$ \\
\hline \multirow[t]{2}{*}{ IL-10 } & F:CCCTTTGCTATGGTGTCCTT & 97 & 35 & 50 \\
\hline & R:TGGTTTCTCTTCCCAAGACC & & & \\
\hline \multirow[t]{2}{*}{$\mid L-1 \beta$} & F:TTCAAGGGGACATTAGGCAG & 158 & 35 & 51 \\
\hline & R:TGTGCTGGTGCTTCATTCAT & & & \\
\hline \multirow[t]{2}{*}{ TNF-a } & $\mathrm{F}: \mathrm{CTCAGCGAGGACAGCAAGG}$ & 108 & 35 & 53 \\
\hline & R:AGGGACAGAACCTGCCTGG & & & \\
\hline \multirow[t]{2}{*}{ MCP-1 } & F:AGAGAGCCAGACGGGAGGAA & 190 & 35 & 56 \\
\hline & R:GTAGCAGCAGGTGAGTGGGG & & & \\
\hline \multirow[t]{2}{*}{ MMP-9 } & F:GGTCTAGGCCCAGAGGTA & 310 & 35 & 57 \\
\hline & R:GGTCGTAGGTCACGTAGC & & & \\
\hline \multirow[t]{2}{*}{ T-bet } & F:TTCAACCAGCACCAGACAGA & 109 & 35 & 62 \\
\hline & R:ACATCCTGTAATGGCTTGTGG & & & \\
\hline \multirow[t]{2}{*}{ GATA-3 } & F:TTCAAGGGGACATTAGGCAG & 78 & 35 & 60 \\
\hline & R:TGGTGGTGGTCTGACAGTTC & & & \\
\hline \multirow[t]{2}{*}{ GAPDH } & F:CTTCATTGACCTCAACTACATGGTCTA & 99 & 35 & 55 \\
\hline & R: GATGA CAAGC TTCCC ATTCT CAG & & & \\
\hline
\end{tabular}

\section{Histological and histochemical examination}

On Day 21, the left hind paws of the $\mathrm{H}_{2} \mathrm{O}$-treated group, the kinsenoside-treated group, and the control group were fixed in $10 \%$ neutral phosphatebuffered formalin. These specimens were decalcified in $10 \%$ EDTA for 2 weeks, embedded in paraffin, and sectioned at $5-\mu \mathrm{m}$ intervals. Hematoxylin and eosin staining, tartrate-resistant acid phosphatase (TRAP) staining, and immunohistochemical staining were performed by following standard methods. For the TRAP assay of osteoclast activity, samples were embedded in paraffin and prepared for TRAP staining. After washing with distilled water, samples were incubated for $60 \mathrm{~min}$ at $37{ }^{\circ} \mathrm{C}$ in darkness in a solution containing Fast Garnet GBC, sodium nitrite, napthol AS-BI phosphoric acid, acetate, and tartrate, which was made using a Leukocyte Acid Phosphatase Assay kit (Sigma-Aldrich, St. Louis, MO). The samples were washed with water, and TRAP-positive multinucleated cells, containing three or more nuclei, were counted under a microscope. For immunohistochemical staining, the cryostat section of joints was fixed in cold acetone for $10 \mathrm{~min}$, washed in PBS, and treated with $0.3 \% \mathrm{H}_{2} \mathrm{O}_{2}$ in absolute methanol for $15 \mathrm{~min}$ to deplete endogenous peroxidase. After blocking nonspecific binding by using $10 \%$ nonfat milk in PBS for $30 \mathrm{~min}$, the sections were incubated with antirabbit MMP-9 Ab (Millipore, MA, USA) or CD $68^{+}$Ab (Abcam, Cambridge, UK) at appropriate dilutions for $1 \mathrm{~h}$ at room temperature, washed, incubated with biotinylated antirabbit IgG, washed and incubated with avidin-biotinylated HRP complex and diaminobenzidine tetrahydrochloride (Elite kit; Vector Laboratories Inc., Burlingame, CA, USA), and counterstained with Mayer's hematoxylin.

\section{Splenocyte preparation and $\mathrm{CD}^{+} \mathrm{T}$ cell isolation}

Splenocytes were prepared by disrupting the spleen between glass slides in complete medium (RPMI 1640 with $10 \%$ FBS and $1 \%$ PSA). After 10 min of centrifugation at $300 \times g$ to separate cells from debris, the cells were washed in RPMI medium, followed by the lysis of erythrocytes by using 0.1X HBSS and 2X HBSS. Splenic CD4 ${ }^{+}$ cells were purified using flow cytometry (BD FACSAria) to perform positive selection with $\mathrm{CD}^{+}$(eBioscience, San Diego, CA., USA). The purity was $>95 \%$.

\section{In vitro Th1 and Th2 cell polarization}

$\mathrm{CD}^{+} \mathrm{T}$ cells $\left(1 \times 10^{6}\right.$ cells/well $)$ were resuspended in complete medium (RPMI 1640 with $10 \%$ FBS and $1 \%$ PSA) and activated with plate-bound $6 \mu \mathrm{g} / \mathrm{ml}$ anti-CD3 (BioLegend, San Diego, CA) and $6 \mu \mathrm{g} / \mathrm{ml}$ anti-CD28 (BioLegend, San Diego, CA) for $24 \mathrm{~h}$. Naive CD4 ${ }^{+}$T cells were incubated with $20 \mathrm{ng} / \mathrm{ml} \mathrm{rIL-12}$ (BioLegend, San Diego, CA), $20 \mu \mathrm{g} / \mathrm{ml}$ anti-IL-4 (BioLegend, San Diego, 
CA), and $20 \mathrm{ng} / \mathrm{ml} \mathrm{rIL-2} \mathrm{(ProSpec-Tany} \mathrm{TechnoGene}$ Ltd., Rehovot Science Park, Israel) for Th1 differentiation. For Th2 cell differentiation, $20 \mu \mathrm{g} / \mathrm{ml} \mathrm{IL-4} \mathrm{(Pro-}$ Spec-Tany TechnoGene Ltd., Rehovot Science Park, Israel) and $10 \mathrm{ng} / \mathrm{ml} \mathrm{rIL-2} \mathrm{(ProSpec-Tany} \mathrm{TechnoGene}$ Ltd., Rehovot Science Park, Israel) were added to the culture medium in the presence of $20 \mathrm{ng} / \mathrm{ml} \mathrm{rIL-2}$. Cells were cultured for 7 days and harvested for the preparation of total RNA.

\section{Statistical analysis}

Results are expressed as the mean \pm standard deviation [17]. All experimental data were analyzed using one-way analysis of variance following the Dunnett test. $P<0.05$ was considered statistically significant. The Mann-Whitney $U$ test was used to determine the severity scores of the kinsenoside group and the $\mathrm{H}_{2} \mathrm{O}$-treated CIA group, and the scores were expressed as the mean \pm SD for each group at each time point. $P<0.05$ was considered statistically significant.

\section{Results}

Effects of kinsenoside on mice with collagen-induced arthritis

We used a mouse CIA model to determine whether kinsenoside exerts suppressive effects on RA. Kinsenoside administered daily significantly suppressed CIA in mice in a dose-dependent manner. Mice treated with 100 and $300 \mathrm{mg} / \mathrm{kg}$ of kinsenoside exhibited significant reductions in incidence and severity of CIA (Fig. 1a). On Day 10 , arthritis incidence and mean severity score for the group treated with $300 \mathrm{mg} / \mathrm{kg}$ of kinsenoside were $3.6 \pm$ 0.5 , respectively, as opposed to $6.6 \pm 1.3$ for the $\mathrm{H}_{2} \mathrm{O}$ treated group. This treatment significantly reduced arthritis severity scores on 0-20 day and arthritis scores and disease incidence attained their maxima after 2nd booster injection in all mouse groups (Fig. $1 \mathrm{~b}$ and c).

\section{Effects of kinsenoside on joint histology}

To investigate the effects of kinsenoside on the progression of CIA, the oral administration of kinsenoside

a
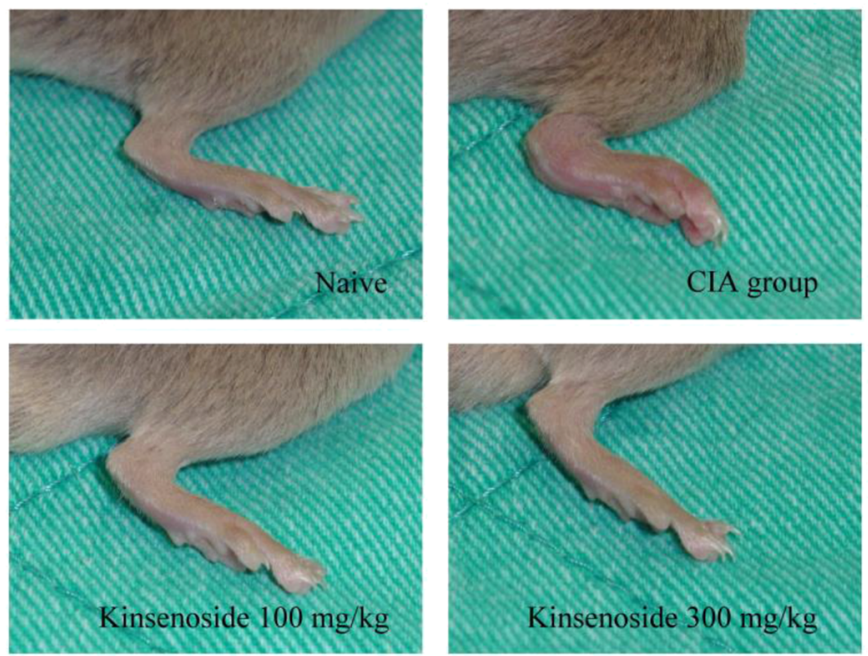

b

c
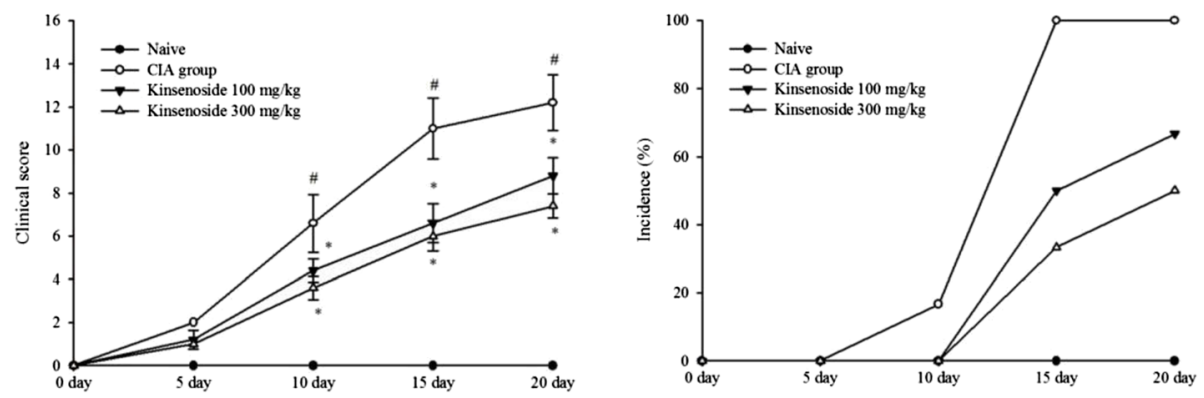

Fig. 1 The effects of kinsenoside on the development and clinical of CIA. a Photograph type (hind paw volume). (b). Clinical scores of CIA were monitored every 5 day after booster immunization. (c)The incidence of arthritic paws overtime was monitored. ${ }^{*} p<0.05$ vs. $\mathrm{H}_{2} \mathrm{O}$-treated group, $n=6$ in each group) 
(100 and $300 \mathrm{mg} / \mathrm{kg}$ ) was initiated 1 day after 2nd booster injection. After sacrificing the mice, we evaluated the histology of the synovial tissues. Figure 2a illustrates that kinsenoside inhibited cartilage and bone destruction, as well as inflammatory responses in the treated group, compared with that in the $\mathrm{H}_{2} \mathrm{O}$-treated CIA group. The treatment of mice with CIA by using kinsenoside resulted in significant reductions in cellular infiltration, pannus formation, and the destruction of cartilage and bone in arthritic joints, with low pathogenic scores.

TRAP + osteoclasts (red staining) were present on the bone surfaces of the mice with CIA not treated with kinsenoside, particularly around the navicular bone. In the kinsenoside-treated mice, however, the accumulation of TRAP+ cells was significantly less than that in the mice not treated with kinsenoside, and navicular bone structure was maintained (Fig. 2b).

Immunohistochemical staining of synovial tissues in the $\mathrm{H}_{2} \mathrm{O}$-treated CIA group revealed high levels of MMP-9 and $\mathrm{CD} 8^{+}$expression. By contrast, mice with CIA treated with kinsenoside exhibited significant reductions in MMP-9 and CD68 ${ }^{+}$expression (Fig. 2c and d).

\section{Kinsenoside inhibits inflammatory cytokines and MMP-9 expression in the joints of mice with collagen-induced arthritis}

Local and circulating cytokine levels were measured in the joint tissues and sera to obtain insight into the mechanisms of beneficial kinsenoside-mediated effects. In Fig. 3, the reverse-transcription polymerase chain reaction (RT-PCR) results indicated the presence of relatively small amounts of IL-1 $\beta$, TNF- $\alpha$, and MMP-9 mRNA in the joints of healthy mice. However, the concentrations of these transcripts exhibited a substantial increase in the joints of the mice with CIA. Kinsenoside treatment significantly reduced elevated levels of IL-1 $\beta$, TNF- $\gamma$ and MMP-9. By contrast, the expression of IL-10 in the joints of mice with CIA was significantly lower than that of healthy mice (Fig. 3), and the administration of $300 \mathrm{mg} / \mathrm{kg}$ of kinsenoside increased IL-10 gene expression to levels comparable with those of the $\mathrm{H}_{2} \mathrm{O}$-treated group. These results suggested that kinsenoside prevented the destruction of connective tissues by simultaneously augmenting IL-10 production and reducing IL- $1 \beta$, TNF- $\alpha$, and MMP-9 production at inflammatory sites in mice with RA.

\section{Kinsenoside downregulates proinflammatory cytokine production}

We performed in vitro assay of CIA-induced cytokine production by mouse splenocytes to clarify whether kinsenoside treatment regulates cytokine production. Equivalent numbers of splenocytes from the $\mathrm{H}_{2} \mathrm{O}$ treated and kinsenoside-treated mice with CIA were cultured with Con A. We measured the production of Th1-related cytokines (IFN- $\gamma$ ), Th2-related cytokines

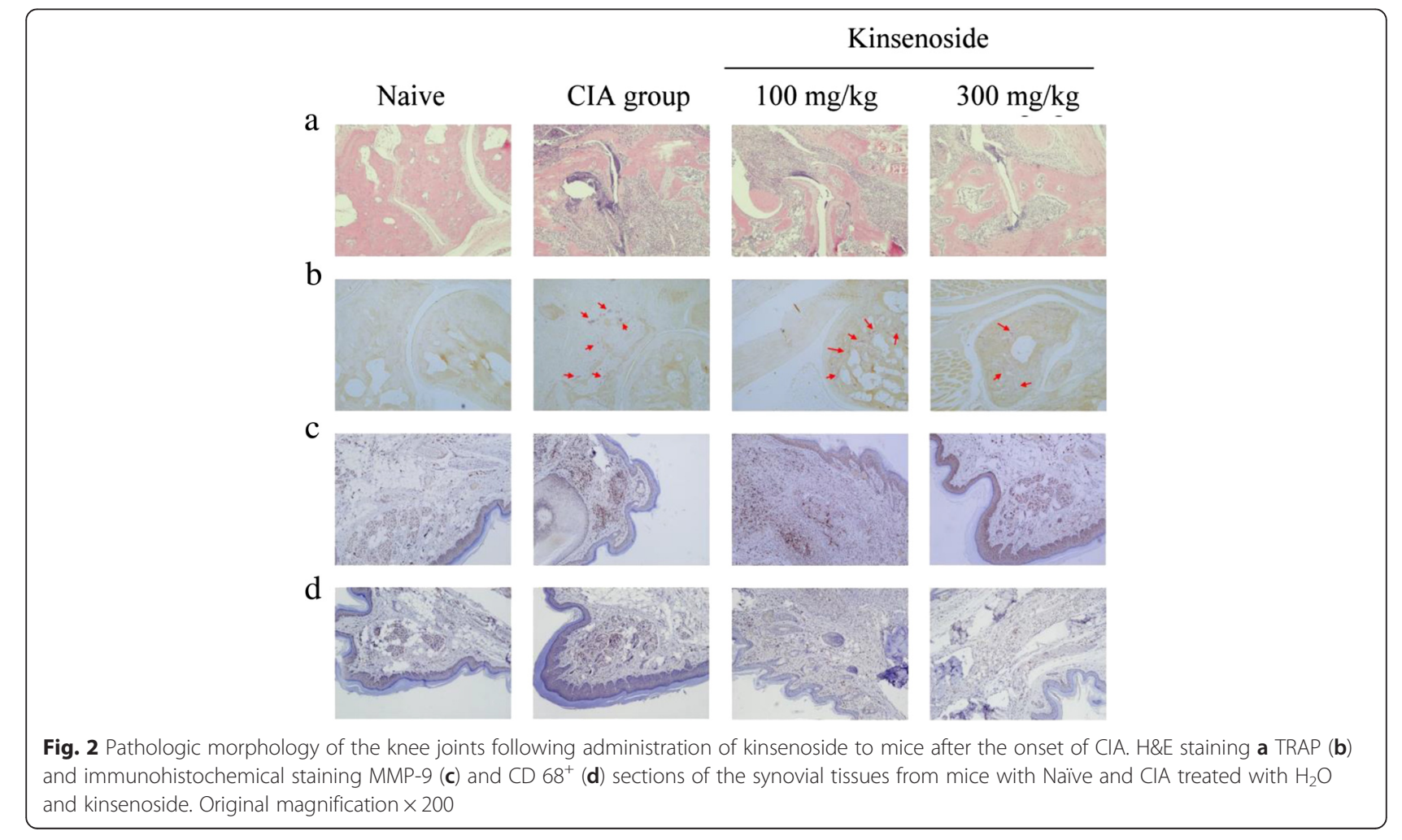




Naive CIA group $100 \quad 300$
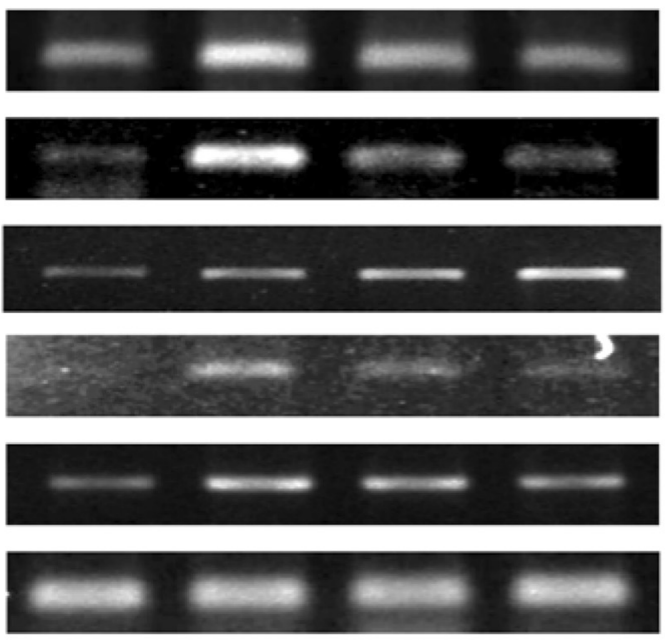

MMP-9

\section{MCP-1}

\section{GAPDH}

b

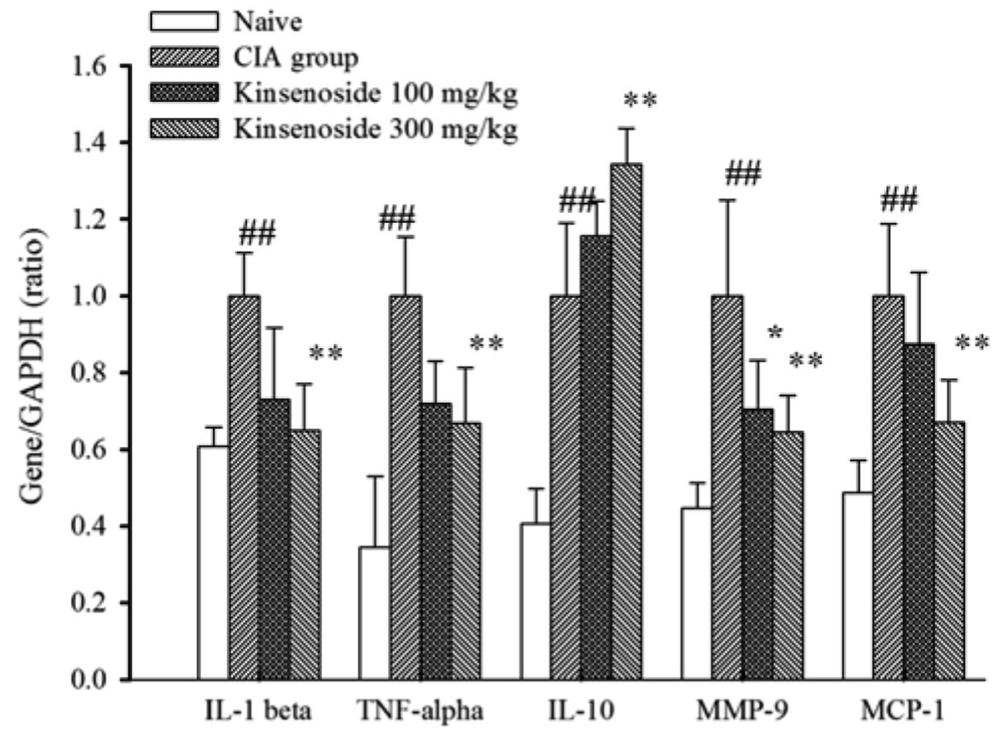

Fig. 3 Effects of kinsenoside on mRNA expression of the inflammatory cytokines, MMP-9 and MCP-1 in the joints of CIA mice. Fragments were amplified by RT-PCR (a). The expression levels of IL-1 $\beta$, TNF-a, IL-10, MMP-9 and mRNA were measured and quantified densitometrically (b). The mice were treated as described in the Materials and methods section. Values were expressed as means $\pm S D, n=6$ in each group. \# $P<0.05$, \#\# $P$ $<0.01$ as compared with the naïve group. ${ }^{*} P<0.05$, ${ }^{*} P<0.01$ as compared with the $\mathrm{H}_{2} \mathrm{O}$-treated group

(IL-10), Th17-related cytokines (IL-17), and proinflammatory cytokines (TNF- $\alpha$ ) in the supernatants of each splenocyte culture. We discovered that the levels of IFN- $\gamma$, IL-17, and TNF- $\alpha$ were significantly suppressed in the supernatants of each of the splenocyte cultures of kinsenoside-treated mice with CIA, compared with that in the $\mathrm{H}_{2} \mathrm{O}$-treated mouse group (Fig. 4a, b, and c).

However, the levels of IL-10 in the splenocytes of the kinsenoside-treated mice were significantly increased compared with that in the $\mathrm{H}_{2} \mathrm{O}$-treated mice (Fig. 4d). These data indicated that kinsenoside suppressed Con Ainduced cytokine production (IFN- $\gamma$, IL-17 and TNF- $\alpha$ ) in the supernatants of each of the splenocyte cultures during the progression of arthritis.

Fluorescence-activated cell sorting analysis of splenocytes We investigated the recruitment of total cells in splenocytes, and measured the effects of kinsenoside on inflammatory cells to evaluate the effects of 


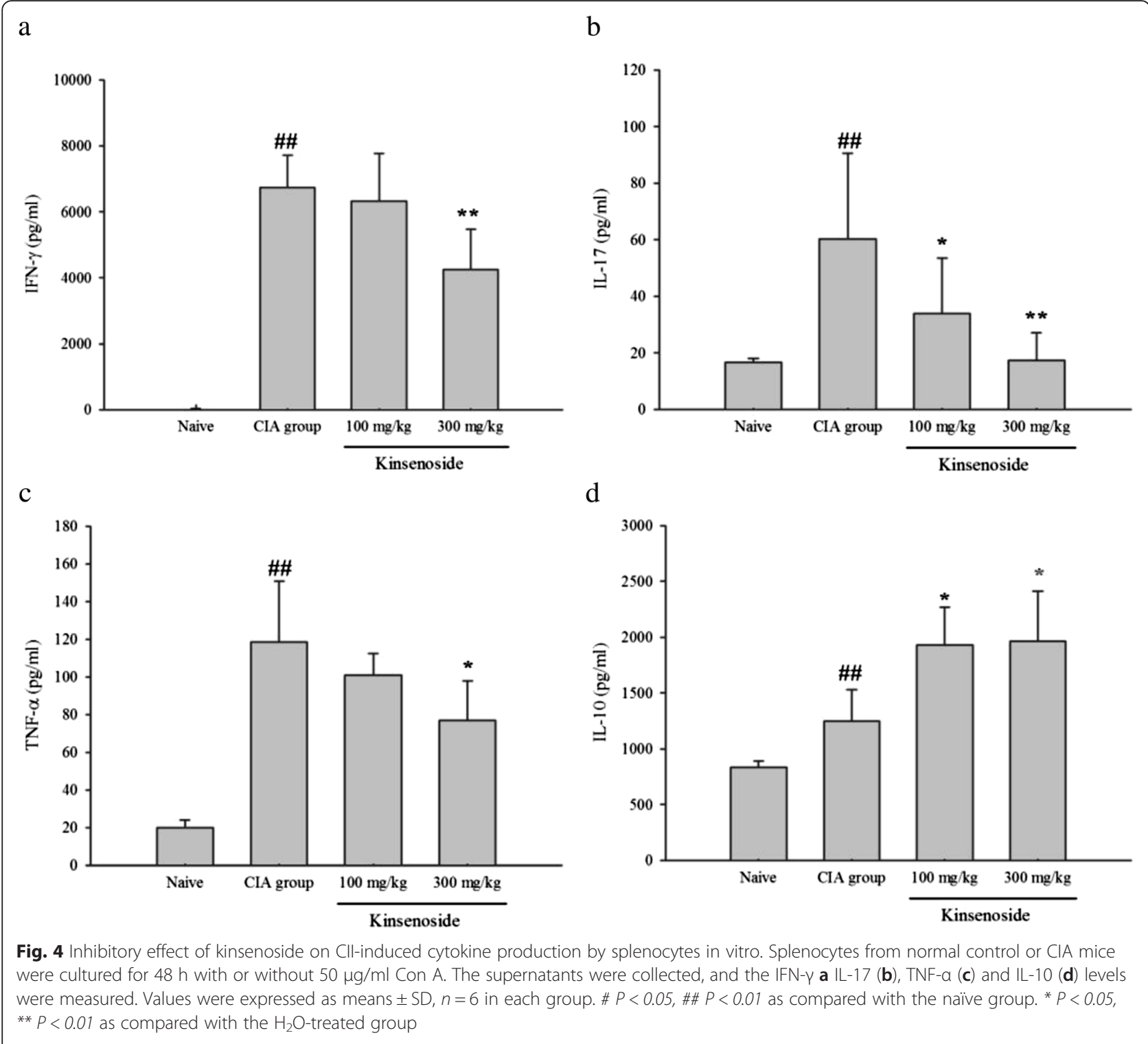

kinsenoside on mice with CIA. The cell population of the splenocytes in the kinsenoside-treated group exhibited a decrease, compared with that in the $\mathrm{H}_{2} \mathrm{O}$ treated controls (Table 2). Fluorescence-activated cell sorting analysis of $\mathrm{CD} 4^{+}, \mathrm{CD} 19^{+}, \mathrm{CD} 25^{+}, \mathrm{CD} 45^{+}$, and Tim $-3^{+}$cell populations, in both healthy mice and those with RA, revealed that the population of Th1 cells produced by $\mathrm{CD} 4^{+} \mathrm{Tim}-3^{+}$cells was higher in the splenocytes of the $\mathrm{H}_{2} \mathrm{O}$-treated group than in those of the other groups. The $\mathrm{CD} 19^{+} \mathrm{CD} 45^{+} \mathrm{B}$ cell population exhibited an increase in the $\mathrm{H}_{2} \mathrm{O}$-treated group, but not in the kinsenoside-treated mice with CIA (Table 2). The Th1 cell population was lower in the kinsenoside-treated CIA group splenocytes $(300 \mathrm{mg} / \mathrm{kg})$ than in the $\mathrm{H}_{2} \mathrm{O}$-treated group (Table 2). The population of Tregs among total $\mathrm{CD}_{4}^{+} \mathrm{CD} 25^{+}$cells in the $\mathrm{H}_{2} \mathrm{O}$-treated CIA group was

Table 2 Effect of kinsenoside on the splenocytes in vivo

\begin{tabular}{lllcr}
\hline The splenocytes (\%) & Control & $\mathrm{H}_{2} \mathrm{O}$ & Kinsenoside $100 \mathrm{mg} / \mathrm{kg}$ & Kinsenoside $300 \mathrm{mg} / \mathrm{kg}$ \\
\hline $\mathrm{CD}^{+}{ }^{+} \mathrm{Tim}-3^{+}$cells & $4.96 \pm 0.63$ & $9.12 \pm 0.79 \# \#$ & $7.62 \pm 0.93^{* *}$ & $7.04 \pm 0.74^{* *}$ \\
$\mathrm{CD} 4^{+} \mathrm{CD} 25^{+}$cells & $8.31 \pm 0.48$ & $6.21 \pm 0.82 \# \#$ & $7.82 \pm 0.91^{* *}$ & $8.26 \pm 0.78^{* *}$ \\
$\mathrm{CD} 19^{+} \mathrm{CD} 45^{+}$cells & $26.99 \pm 4.56$ & $36.2 \pm 2.52 \# \#$ & $25.84 \pm 5.64^{* *}$ & $23.75 \pm 3.98^{* *}$ \\
\hline
\end{tabular}

Population of the splenocytes in normal control and CIA mice. The cell populations of the CD4 ${ }^{+} \mathrm{Tim}-3^{+}, \mathrm{CD}^{+} \mathrm{CD} 25^{+}$and $\mathrm{CD} 19^{+} \mathrm{CD} 45^{+}$cells in the splenocytes. Values were expressed as means $\pm \mathrm{SD}, n=6$ in each group. ${ }^{\# \#} P<0.01$ as compared with the control group. ${ }^{* *} P<0.01$ as compared with the $\mathrm{H}_{2} \mathrm{O}$-treated group 

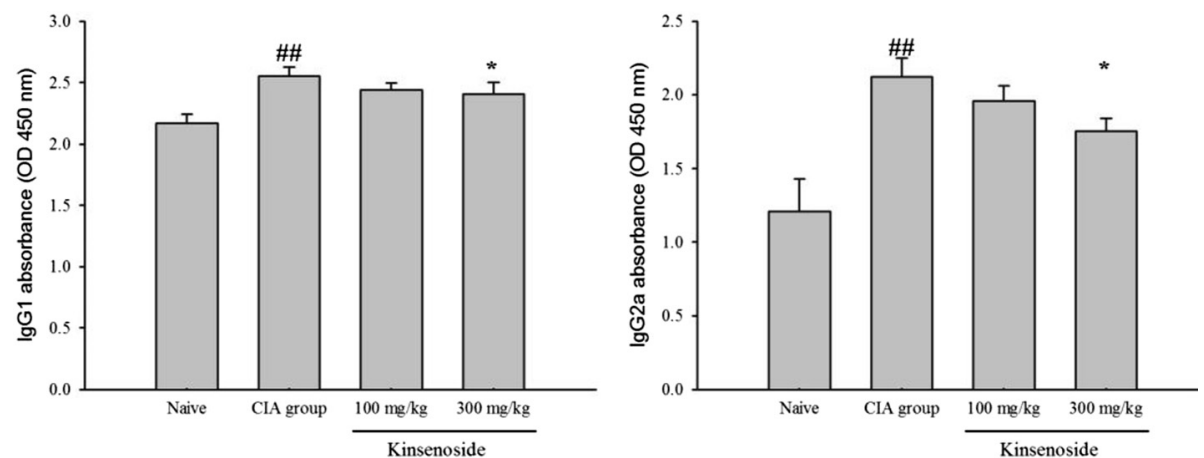

Fig. 5 Effects of kinsenoside on anti-Cll IgG1 and IgG2a. Serum was obtained from 6 mice of each group on day 21 after the booster injection. Values were expressed as means $\pm S D, n=6$ in each group. $\# P<0.05$, \#\#P<0.01 as compared with the naiive group. ${ }^{*} P<0.05$, ${ }^{*} P<0.01$ as compared with the $\mathrm{H}_{2} \mathrm{O}$-treated group

lower than that in the control group, but higher than that in the kinsenoside-treated groups (Table 2).

\section{Kinsenoside downregulates Ag-specific B cell responses} We assessed the levels of CII-specific IgG1 and IgG2a antibodies, and the kinsenoside-treated group exhibited downregulation of anti-CIA IgG1 and IgG2a antibody production (Fig. 5).

\section{Effects of kinsenoside on the modulation of Th1/Th2 cell polarization}

We investigated whether kinsenoside would produce a similar effect under Th1- and Th2-polarized conditions. $\mathrm{CD} 4{ }^{+} \mathrm{T}$ cells were activated using anti-CD3/anti-CD28 and cultured in kinsenoside-containing medium under Th1-inducing or Th2-inducing conditions. To investigate the direct effect of kinsenoside on Th1- and Th2-specific cytokine gene expression, we performed real-time RT-
PCR by using RNA from activated $\mathrm{CD} 4^{+} \mathrm{T}$ cells. Our data (Fig. 6) indicated that kinsenoside did not affect T-bet expression in the Th1-polarized culture, or GATA-3 expression in the Th2-polarized culture.

\section{Discussion}

In this study, we demonstrated the antiinflammatory and antiarthritic effects of kinsenoside on mice with CIA, which were used as an experimental model of RA. We performed this study to elucidate the effects and modulation of kinsenoside on a CIA model. In the CIAinduced animal model, kinsenoside improved the severity of arthritis, inhibited the progression of CIA, and increased IL-10 levels. Kinsenoside markedly inhibited clinical signs of joint swelling, and significantly reduced inflammatory cell infiltration and bone erosion. These results indicated that kinsenoside exerts a distinct preventive effect on CIA. a
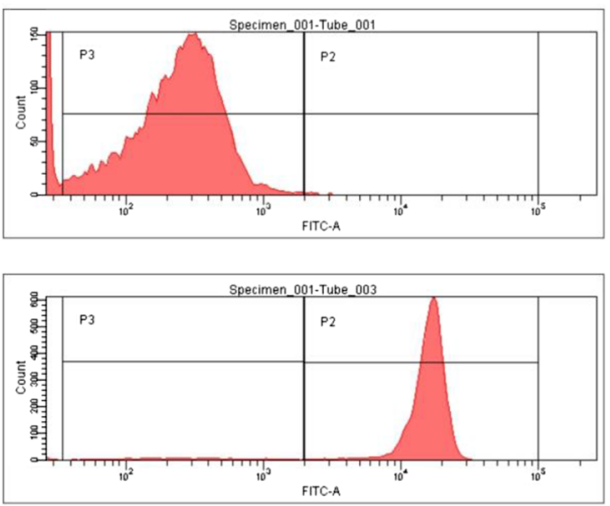

$\mathrm{b}$

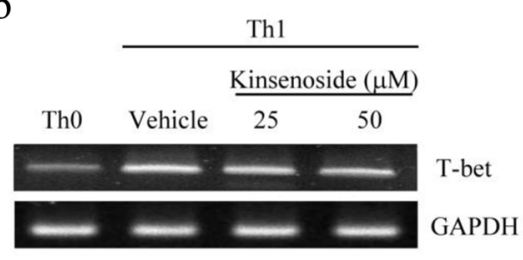

c

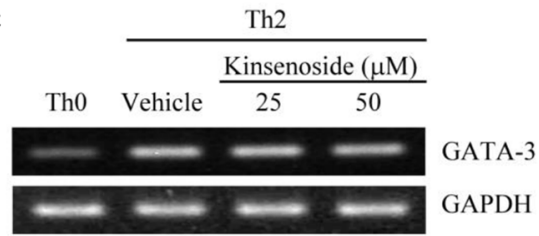

Fig. 6 The effect of kinsenoside on helper T-cell differentiation in Th1 or Th2 polarized conditions. Th0 cells (CD4 ${ }^{+}$) were sorted by FACSAria for RT-PCR analysis. FACSAria (BD Biosciences) was used to sort Splenic CD4+ cellswith the purity of $>95 \%$ (a). Gene expression was measured by RTPCR for T-bet (b), GATA-3 (c) in polarized splenocytes and compared with non-stimulated splenocytes (day 7). RT-PCR data were normalized to $\mathrm{GAPDH}$ expression and presented as means $\pm \mathrm{SD}, n=3$ in each group. \#\#P<0.01as compared with the vehicle group 
CIA has been widely used as an animal model in RA research. It is a chronic inflammatory disease characterized by infiltration of the synovial membrane and is associated with the destruction of joints. In addition, CIA more closely resembles human RA in clinical, histological, and immunological features, as well as genetic linkage than do other experimental arthritis models [18]. Therefore, paw swelling and arthritis scores were used to measure the antiarthritic effects of various drugs on the development of the chronic inflammation of CIA. We demonstrated that the oral administration of kinsenoside produced a strong antiarthritic effect capable of reducing CIA paw edema and swelling, which was indicated by the arthritis score. RA-induced inflammation mainly occurs in the synovium and joints, which can be intuitively deduced from the results of histopathological assays. Histologically, we observed significant attenuation in the cellular infiltration of the synovium, synovial hyperplasia, and cartilage damage in mice treated with kinsenoside. In a previous study, inflammatory cytokines induced cell infiltration in joints and increased osteoclast differentiation from monocytes to attenuate disease progression and joint destruction [19]. Hsiao et al. discovered that kinsenoside suppressed osteoclastogenesis [20]. Histological analysis of the joint area of mice with CIA revealed that kinsenoside treatment markedly inhibited the infiltration of inflammatory cells, including numerous $\mathrm{TRAP}^{+}$cells (osteoclasts), as well as severe osteolytic bone destruction associated with arthritic inflammation. Kinsenoside also decreased the expression of MMP-9 and CD $68^{+}$cells (macrophages) in inflamed joints. Thus, our research demonstrated that kinsenoside could protect affected joints against cartilage destruction and bone erosion, and reduced cellular infiltration and synovial hyperplasia in joints.

Chronic inflammation involves the release of several mediators that are responsible for pain, as well as the destruction of bone and cartilage that can lead to severe disability [21]. However, macrophages, the major effectors of synovitis, operate through cytokine secretion, which includes TNF- $\alpha$, IL-1 $\beta$, and IL-6 [22]. Macrophages influence joint inflammation and the destruction of cartilage and bone in patients with RA [23], which can regulate the production of proinflammatory cytokines, including IL-1 $\beta$ and IL- 6 in vitro [24], and stimulate inflammatory cells to secrete MCP-1 and produce MMP-9 [2]. A recent study reported that at the site of joint inflammation, the level of MCP-1 is increased in the blood, synovial fluid, and synovial tissue of patients with RA and OA, primarily by monocytes and lymphocytes [25]. The role of MCP-1 in an inflamed RA joint may be the recruitment of mononuclear phagocytes. Cytokine and chemokine are responsible for the migration and accumulation of leukocytes at inflammatory sites. MMP-9 plays a crucial role in the migration of macrophages in RA [26]. Upregulating the production of MMP-9 could degrade the cartilage matrix by stimulating proinflammatory cytokines [27]. Researchers have recognized that MMP-9 plays an essential role in the degradation of connective tissue components in the cartilage of patients with RA. The expression and production of MMP-9 is regulated at the transcriptional level by proinflammatory cytokines [28]. A reduction in disease severity and bone resorption could be caused by the blockage of these molecules [29], whereas IL-4 and IL-10 possess potent antiinflammatory characteristics and can suppress cartilage and bone pathology in patients with RA [30]. In the present study, we demonstrated that kinsenoside significantly decreased the CIAaugmented gene expression of TNF- $\alpha$, IL-1 $\beta$, MMP-9, and MCP-1, and increased the gene expression of IL-10 in the inflamed joints of mice with CIA. Our previous study, which demonstrated that LPS-induced gene expression of TNF- $\alpha$, IL- $1 \beta$ and MCP- 1 is inhibited and the gene expression of IL-10 is enhanced by kinsenoside in macrophages, supports these results. Therefore, we concluded that kinsenoside can suppress cartilage degradation in the inflamed joints of patients with RA.

Recent studies have demonstrated that numerous RA patients exhibit changes in morphology and inflammatory phenotypes in synovial tissue, characterized histologically by hypertrophy and the infiltration of leucocytes and monocytes or macrophages [31]. CIA has provided scientists with a translational model that defines the role of inflammatory cytokines in RA, particularly TNF- $\alpha$, IL-1 $\beta$, and IL-17 [32]. Therefore, RA therapy is expected to rapidly control inflammation, suppress progressive joint destruction, and be safe to use. A previous study by Hsiao et al. [11] reported that kinsenoside could effectively suppress macrophages, a critical pathway for driving proinflammatory cytokine production. Our results indicated that the administration of kinsenoside to mice with CIA inhibited IFN- $\gamma$ and TNF- $\alpha$ production and increased IL-10 production in splenocytes by stimulating Con A production. The expression of IL-17, induced mainly by Th17 cells, in the synovium has been associated with the disease severity of RA [33]. IL-17 increases the activation of synoviocytes and expression of other cytokines, thereby contributing to cartilage and bone destruction [34]. In patients with RA and in CIA models, IL-17 was detected at increased levels in joints, and elevated levels of IL-17A were observed in the inflamed synovium [35]. In this study, the administration of kinsenoside to CIA mice inhibited the secretion of IL-17, suggesting that the antiinflammatory action of kinsenoside is associated with a significant reduction in the release of IL-17. Thus, kinsenoside downregulated the production of the proinflammatory cytokines TNF- $\alpha$, IFN- $\gamma$ and IL-17 in the splenocytes, and increased the levels of antiinflammatory cytokine IL-10, which ameliorated the disease. 
In the past, scientists have asserted that RA is a Th1associated disorder [36], and considered Th1 cells to be the principal T-cell players in the pathogenesis of RA. One previous study reported that Th1 cells were observed in the joints of patients with RA [37]. Tregs from healthy individuals or patients with RA receiving treatment suppressed the proliferation of responder $\mathrm{T}$ cells and reduced IFN- $\gamma$ production [38]. Additionally, one study reported that Tregs isolated from the synovial fluid or peripheral blood of patients with RA suppressed the proliferation of autologous $\mathrm{T}$ cells in vitro [39]. Therefore, Tregs suppress the proliferation and cytokine production of CD4 T cells through the inhibition of IL-2 transcription. Furthermore, Tregs are crucial for the suppression of potentially harmful excessive immune responses [5]. However, kinsenoside would produce a similar effect under Th1- and Th2- polarized conditions in kinsenoside-containing medium under Th1-inducing or Th2-inducing conditions. These results indicate that kinsenoside upregulates the cell population of $\mathrm{CD}^{+} \mathrm{CD} 25^{+}$Tregs, thereby attenuating the progression of CIA. Our analysis, conducted using flow cytometry, demonstrated that the administration of kinsenoside reduced the cell population of $\mathrm{CD} 19^{+} \mathrm{CD} 45^{+}$and $\mathrm{CD} 4$ ${ }^{+} \mathrm{Tim}-3^{+}$, and increased the cell population of $\mathrm{CD} 4{ }^{+} \mathrm{CD} 25^{+}$ cells in splenocytes. These results suggested that kinsenoside downregulated Th1-cell response, thereby mediating antiinflammatory functions. Kinsenoside might also indirectly suppress Th1 response by increasing the number of Tregs. However, the increase in the production of IL-10 in splenocytes by kinsenoside is evidence against a shift toward Th2 responses. However, the naïve CD4+ cells isolated from healthy mice provided evidence that kinsenoside did not influence Th1 or Th2 differentiation ex vivo. According to our previous data, kinsenoside was responsible for the suppression of airway hyperresponsiveness in mice who inhaled OVA through the modulation of Tregs [13]. Therefore, the inhibition of Th1 cytokines by using kinsenoside is dependent of its action by modulating Tregs. Tregs can also modulate monocyte function and directly inhibit the immunoglobulin response of B cells [40]. Our results demonstrated that kinsenoside enhanced the expression of Tregs, thereby decreasing the $\mathrm{B}$ cell population. T-cell-dependent antigen B-cell responses exhibited similar changes and were consistent with these findings. We demonstrated that kinsenoside significantly reduced the levels of CII-specific IgG1 and IgG2a Abs in the serum of mice with RA. Kinsenoside treatment caused a deficiency in the generation of deleterious autoimmune antibody responses, suggesting that kinsenoside played an essential role in regulating B cell trafficking and antibody production.

\section{Conclusion}

We confirmed that kinsenoside inhibits the inflammatory mediator on RA in our in vivo study. Kinsenoside effectively mitigated the destruction of cartilage and inflammatory responses in mice with CIA. These therapeutic effects partially resulted from the direct suppression of MMP-9 production in the joints by inhibiting inflammatory cytokines, including IL-1 $\beta$ and TNF- $\alpha$. These results suggest that kinsenoside inhibits the inflammatory mediator release in a CIA induced arthritis mouse model by regulating the $\mathrm{T}$ cells responses.

\section{Competing interests}

The authors declare that they have no competing interests.

\section{Authors' contributions}

$\mathrm{HBH}$ performed experiments and analyzed data. $\mathrm{HBH}$ and WCL designed the study. $\mathrm{HBH}$ and WCL induced the arthritis; JBW did the extract HPLC analysis. $\mathrm{HBH}$ and $\mathrm{CCH}$ were responsible for animal's treatment. $\mathrm{HL}$ helps for data interpretation. $\mathrm{HL}$ and $\mathrm{WCL}$ realized by read and approved the final manuscript. All authors read and approved the final manuscript.

\section{Acknowledgements}

This study was supportred by grants from the National Science Council of the Republic of China (NSC 101-2320-B-039-019).

\section{Author details}

${ }^{1}$ Department of Life Sciences, National Chung Hsing University, Taichung, Taiwan, ROC. ${ }^{2}$ Department of Animal Science and Biotechnology, Tunghai University, Taichung, Taiwan, ROC. ${ }^{3}$ School of Pharmacy, China Medical University, Taiwan. 91 Hsueh Shih Road, Taichung 404, Taiwan, ROC.

Received: 27 August 2015 Accepted: 16 February 2016

Published online: 25 February 2016

References

1. Firestein GS. Evolving concepts of rheumatoid arthritis. Nature. 2003; 423(6937):356-61

2. Mclnnes IB, Schett $G$. Cytokines in the pathogenesis of rheumatoid arthritis, Nat Rev Immunol. 2007;7(6):429-42.

3. Choy EH, Panayi GS. Cytokine pathways and joint inflammation in rheumatoid arthritis. N Engl J Med. 2001;344(12):907-16.

4. Miossec $P$, van den Berg W. Th1/Th2 cytokine balance in arthritis. Arthritis Rheum. 1997:40(12):2105-15.

5. Sakaguchi S, Yamaguchi T, Nomura T, Ono M. Regulatory T cells and immune tolerance. Cell. 2008;133(5):775-87.

6. Doan T, Massarotti E. Rheumatoid arthritis: an overview of new and emerging therapies. J Clin Pharmacol. 2005;45(7):751-62.

7. Umar S, Kumar A, Sajad M, Zargan J, Ansari M, Ahmad S, et al. Hesperidin inhibits collagen-induced arthritis possibly through suppression of free radical load and reduction in neutrophil activation and infiltration. Rheumatol Int. 2013;33(3):657-63.

8. Wang M, Li K, Nie Y, Wei Y, Li X. Antirheumatoid arthritis activities and chemical compositions of phenolic compounds-rich fraction from urtica atrichocaulis, an endemic plant to China. Evid based complement alternat med: eCAM. 2012;2012:818230.

9. Institute of Research on Traditional Chinese Medicine of Fujian Province, 1982. Record of Fujian Materia Medica No. 2. Fujian Science\&Technology Press, pp. 215-217.

10. Lin CC, Huang PC, Lin JM. Antioxidant and hepatoprotective effects of anoectochilus formosanus and gynostemma pentaphyllum. Am J Chin Med. 2000;28(1):87-96.

11. Hsiao HB, Wu JB, Lin H, Lin WC. Kinsenoside isolated from anoectochilus formosanus suppresses LPS-stimulated inflammatory reactions in macrophages and endotoxin shock in mice. Shock. 2011;35(2):184-90.

12. Shih CC, Wu YW, Lin WC. Aqueous extract of anoectochilus formosanus attenuate hepatic fibrosis induced by carbon tetrachloride in rats. Phytomedicine : international journal of phytotherapy and phytopharmacology. 2005;12(6-7):453-60.

13. Hsieh CC, Hsiao HB, Lin WC. A standardized aqueous extract of anoectochilus formosanus modulated airway hyperresponsiveness in an 
OVA-inhaled murine model. Phytomedicine : international journal of phytotherapy and phytopharmacology. 2010;17(8-9):557-62.

14. Wu JB, Lin WL, Hsieh CC, Ho HY, Tsay HS, Lin WC. The hepatoprotective activity of kinsenoside from anoectochilus formosanus. Phytother res : PTR. 2007;21(1):58-61.

15. Jung EG, Han Kl, Hwang SG, Kwon HJ, Patnaik BB, Kim YH, et al. Brazilin isolated from caesalpinia sappan $L$ inhibits rheumatoid arthritis activity in a type-Il collagen induced arthritis mouse model. BMC complement altern med. 2015;15:124

16. Poosarla A, Rao DN, Athota RP, Sunkara VG. Modulation of T cell proliferation and cytokine response by plumbagin, extracted from plumbago zeylanica in collagen induced arthritis. BMC Complement Altern Med. 2011;11:114.

17. Delaisse JM, Engsig MT, Everts V, del Carmen Ovejero M, Ferreras M, Lund L, et al. Proteinases in bone resorption: obvious and less obvious roles. Clin chim acta; international journal of clinical chemistry. 2000;291(2):223-34.

18. Du F, Lu LJ, Fu Q, Dai M, Teng JL, Fan W, et al. T-614, a novel immunomodulator, attenuates joint inflammation and articular damage in collagen-induced arthritis. Arthritis Res Ther. 2008;10(6):R136.

19. OU Y, Li W, Li X, Lin Z, Li M. Sinomenine reduces invasion and migration ability in fibroblast-like synoviocytes cells co-cultured with activated human monocytic THP-1 cells by inhibiting the expression of MMP-2, MMP-9, CD147. Rheumatol Int. 2011;31(11):1479-85.

20. Hsiao HB, Lin H, Wu JB, Lin WC. Kinsenoside prevents ovariectomy-induced bone loss and suppresses osteoclastogenesis by regulating classical NFkappaB pathways. Osteoporos int : a journal established as result of cooperation between the European Foundation for Osteoporosis and the National Osteoporosis Foundation of the USA. 2013;24(5):1663-76.

21. Baker JR, Bumstead N, Huchzermeyer FW, Reece RL. Book reviews. Avian pathol: journal of the WVA. 1997;26(2):441-9.

22. Boissier MC, Semerano L, Challal S, Saidenberg-Kermanac'h N, Falgarone G. Rheumatoid arthritis: from autoimmunity to synovitis and joint destruction. J Autoimmun. 2012;39(3):222-8.

23. Feldmann M, Brennan FM, Maini RN. Role of cytokines in rheumatoid arthritis. Annu Rev Immunol. 1996;14:397-440.

24. Carteron NL. Cytokines in rheumatoid arthritis: trials and tribulations. Mo Med Today. 2000;6(8):315-23.

25. Stankovic A, Slavic V, Stamenkovic B, Kamenov B, Bojanovic M, Mitrovic DR. Serum and synovial fluid concentrations of CCL2 (MCP-1) Chemokine in patients suffering rheumatoid arthritis and osteoarthritis reflect disease activity. Bratisl Lek Listy. 2009;110(10):641-6.

26. Jovanovic DV, Martel-Pelletier J, Di Battista JA, Mineau F, Jolicoeur FC, Benderdour $\mathrm{M}$, et al. Stimulation of 92-kd gelatinase (matrix metalloproteinase 9) production by interleukin-17 in human monocyte/ macrophages: a possible role in rheumatoid arthritis. Arthritis Rheum. 2000; 43(5):1134-44.

27. Smolen JS, Steiner G. Therapeutic strategies for rheumatoid arthritis. Nat Rev Drug Discov. 2003;2(6):473-88.

28. Liang KC, Lee CW, Lin WN, Lin CC, Wu CB, Luo SF, et al. Interleukin-1 beta induces MMP-9 expression via p42/p44 MAPK, p38 MAPK, JNK, and nuclear factor-kappaB signaling pathways in human tracheal smooth muscle cells. J Cell Physiol. 2007;211(3):759-70.

29. Schett G, Stach C, Zwerina J, Voll R, Manger B. How antirheumatic drugs protect joints from damage in rheumatoid arthritis. Arthritis Rheum. 2008; 58(10):2936-48.

30. Juarranz Y, Abad C, Martinez C, Arranz A, Gutierrez-Canas I, Rosignoli F, et al. Protective effect of vasoactive intestinal peptide on bone destruction in the collagen-induced arthritis model of rheumatoid arthritis. Arthritis Res Ther. 2005;7(5):R1034-45.

31. Haywood L, McWilliams DF, Pearson Cl, Gill SE, Ganesan A, Wilson D, et al. Inflammation and angiogenesis in osteoarthritis. Arthritis Rheum. 2003;48(8): 2173-7.

32. Koenders MI, Joosten LA, van den Berg WB. Potential new targets in arthritis therapy: interleukin (IL)-17 and its relation to tumour necrosis factor and IL1 in experimental arthritis. Ann rheum dis. 2006;65 Suppl 3:iii29-33.

33. Kirkham BW, Lassere MN, Edmonds JP, Juhasz KM, Bird PA, Lee CS, et al. Synovial membrane cytokine expression is predictive of joint damage progression in rheumatoid arthritis: a two-year prospective study (the DAMAGE study cohort). Arthritis Rheum. 2006;54(4):1122-31.

34. Lubberts E, Koenders MI, Oppers-Walgreen B, van den Bersselaar L, Coenende Roo CJ, Joosten LA, et al. Treatment with a neutralizing anti-murine interleukin-17 antibody after the onset of collagen-induced arthritis reduces joint inflammation, cartilage destruction, and bone erosion. Arthritis Rheum. 2004;50(2):650-9.

35. Lubberts E, Joosten LA, Oppers B, van den Bersselaar L, Coenen-de Roo CJ, Kolls JK, et al. IL-1-independent role of IL-17 in synovial inflammation and joint destruction during collagen-induced arthritis. J Immunol. 2001;167(2): 1004-13.

36. Pasare C, Medzhitov R. Toll pathway-dependent blockade of CD4 + CD25+ T cell-mediated suppression by dendritic cells. Science. 2003;299(5609):1033-6.

37. Kageyama Y, Koide Y, Yoshida A, Uchijima M, Arai T, Miyamoto S, et al. Reduced susceptibility to collagen-induced arthritis in mice deficient in IFNgamma receptor. J Immunol. 1998;161(3):1542-8.

38. Aarvak T, Chabaud M, Kallberg E, Miossec P, Natvig JB. Change in the Th1/ Th2 phenotype of memory T-cell clones from rheumatoid arthritis synovium. Scand J Immunol. 1999:50(1):1-9.

39. Ehrenstein MR, Evans JG, Singh A, Moore S, Warnes G, Isenberg DA, et al. Compromised function of regulatory T cells in rheumatoid arthritis and reversal by anti-TNFalpha therapy. J Exp Med. 2004;200(3):277-85.

40. Lim HW, Hillsamer $\mathrm{P}$, Banham AH, Kim CH. Cutting edge: direct suppression of B cells by CD4+ CD25+ regulatory T cells. J Immunol. 2005;175(7):4180-3.

\section{Submit your next manuscript to BioMed Central and we will help you at every step:}

- We accept pre-submission inquiries

- Our selector tool helps you to find the most relevant journal

- We provide round the clock customer support

- Convenient online submission

- Thorough peer review

- Inclusion in PubMed and all major indexing services

- Maximum visibility for your research

Submit your manuscript at www.biomedcentral.com/submit
) Biomed Central 